\title{
Human Acute Gastroenteritis Associated with Arcobacter butzleri
}

Tuba Kayman, M.D., Halil Ibrahim Atabay, Ph.D., ${ }^{2}$ Seçil Abay, Ph.D., ${ }^{3}$ Harun Hızlisoy, M.Sc., ${ }^{3}$ Celenk Molva, M.Sc., and Fuat Aydin, Ph.D., ${ }^{3}$ Department of Clinical Microbiology, Kayseri Education and Research Hospital, Kayseri, Turkey, ${ }^{2}$ Department of Medical Microbiology, Faculty of Medicine, Sifa University, Izmir, Turkey, ${ }^{3}$ Department of Microbiology, Faculty of Veterinary Medicine, Erciyes University, Kayseri, Turkey, and ${ }^{4}$ Department of Food Engineering, Faculty of Engineering, Izmir Institute of Technology, Izmir, Turkey

\section{Introduction}

Arcobacter spp. are considered emerging food-borne pathogens (1). Contaminated water and meat play an important role in the transmission of these bacteria to humans $(2,3)$. Currently, the genus Arcobacter has 13 recognized species: A. butzleri, $A$. cryaerophilus, A. skirrowii, A. nitrofigilis, A. cibarius, A. halophilus, A. mytili, A. thereius, A. marinus, A. trophiarum, A. defluvii, A. molluscorum, and $A$. ellisii $(4,5)$. Only three species, namely, A. butzleri, A. cryaerophilus, and $A$. skirrowii, have been associated with human and animal diseases (1). These microorganisms cause a number of infections, such as abortion, mastitis, and septicemia, in animals. In humans, they have been reported to cause gastrointestinal tract infections and septicemia $(6,7)$. Arcobacter septicemia secondary to underlying diseases, such as cirrhosis (8) and acute gangrenous appendicitis (9), has also been documented in humans.

The role of other Arcobacter species in human and animal diseases remains unclear (1). It has been reported that Arcobacter species are found more commonly on poultry rather than red meat (10), suggesting that poultry may be a major reservoir for the pathogen. We report here a patient with abdominal pain, diarrhea, nausea, and sweating from whom $A$. butzleri was isolated. This is the first documented human case of $A$. butzleri gastroenteritis in Turkey.

\section{Case Report}

A 30-year-old male patient with acute abdominal pain, diarrhea, nausea,

Corresponding Author: Fuat Aydin, Ph.D., Department of Microbiology, Faculty of Veterinary Medicine, Erciyes University, Kayseri, Turkey. Tel.: +903523382272144. Fax: +9035233727 40. E-mail: faydin23@hotmail.com and sweating was admitted to the Kayseri Education and Research Hospital, Kayseri, Turkey. The patient had experienced four episodes of diarrhea but no vomiting. He had no other signs and symptoms of disease. The patient's physical examination was unremarkable. A stool sample was collected from the patient and submitted to the microbiology laboratory for routine enteric bacterial culture and an ova and parasite examination.

Macroscopically, the stool specimen was watery, with no gross blood or mucus observed. On microscopic examination, the stool specimen was negative for the presence of erythrocytes, leukocytes, protozoa, and parasite eggs. The stool specimen was plated onto eosin methylene blue agar (Oxoid, UK) and Hektoen enteric agar (Merck, Germany) for isolation of conventional enteric pathogens as well as modified charcoal cefoperazone deoxycholate agar (mCCDA) (Oxoid) for the cultivation of Campylobacter species. The eosin methylene blue and Hektoen enteric agars were incubated at $37^{\circ} \mathrm{C}$ under aerobic conditions for 18 to $24 \mathrm{~h}$. The mCCDA plate was incubated for 48 to $72 \mathrm{~h}$ at $42^{\circ} \mathrm{C}$ in a microaerophilic atmosphere, which was achieved by using a microaerophilic gas-generating kit (Oxoid). The media used for the culture of routine enteric pathogens (Salmonella and Shigella spp.) were negative for these organisms. However, on the mCCDA plate, grey-white colonies with a distinct metallic sheen were observed. All colonies growing on the mCCDA appeared similar, with no other colonial morphotypes observed.

Three colonies from mCCDA were subcultured to blood agar plates containing 5\% defibrinated sheep blood to ensure purity of the isolate. After overnight incubation, the isolate was confirmed as a gram-negative rod by Gram-stained smear, and a number of phenotypic tests were performed, including the oxidase test, the catalase test, ability to grow at temperatures ranging from 25 to $42^{\circ} \mathrm{C}$, growth on MacConkey agar at 15 and $25^{\circ} \mathrm{C}$, a wet-preparation motility test under phase-contrast microscopy, urease production, nitrate reduction, $\mathrm{H}_{2} \mathrm{~S}$ production, hydrolysis of hippurate, and susceptibility to $30 \mu \mathrm{g}$ of nalidixic acid and $30 \mu \mathrm{g}$ of cephalothin by the disk susceptibility test. The antibiotic susceptibility pattern of the isolate against several other antibiotics was also determined. The isolate was presumptively identified as Arcobacter sp. on the basis of colonial morphology, growth characteristics, and biochemical reactions, as described by Aydin et al. (10).

The putative isolate was then subjected to a genus-specific PCR and multiplex PCR (mPCR) for identification to the genus and species level, respectively. For the genus-specific PCR, the primer combination ARCOIARCOII, targeting a section of the 16S rRNA genes, was used (11). Each amplification process was performed in duplicate, using a $25-\mu \mathrm{l}$ reaction mixture containing $2 \mathrm{ml}$ template DNA, $2.5 \mathrm{ml}$ of $10 \times$ PCR buffer $[750 \mathrm{mM}$ Tris- $\mathrm{HCl}$, $\mathrm{pH} 8.8,200 \mathrm{mM}\left(\mathrm{NH}_{4}\right)_{2} \mathrm{SO}_{4}, 0.1 \%$ ( vol/ vol) Tween 20, and $1.5 \mathrm{mM} \mathrm{MgCl} 2$ ], 10 $\mu \mathrm{M}$ of each primer, $0.2 \mathrm{mM}$ each of the four dNTPs (Fermentas, Germany), and 1.5 U Taq DNA polymerase (Fermentas, Germany). The samples were subjected to an initial denaturation step $\left(94^{\circ} \mathrm{C}\right.$ for $5 \mathrm{~min}$ ), followed by 35 amplification cycles. Each amplification cycle consisted of $1 \mathrm{~min}$ at $94^{\circ} \mathrm{C}$ (denaturation), $1 \mathrm{~min}$ at $56^{\circ} \mathrm{C}$ (primer annealing), and $1 \mathrm{~min}$ at $72^{\circ} \mathrm{C}$ (primer extension). A primer extension step $\left(72^{\circ} \mathrm{C}\right.$ for $7 \mathrm{~min}$ ) followed the final amplification cycle. The amplified products were resolved in $0.6 \%$ (wt/vol) Tris-acetate-EDTA) TAE agarose gel, and the band patterns were analyzed in the gel documentation 
system (Vilber Lourmat, France). Sterile distilled water served as the negative control. The 1223-bp region of $16 \mathrm{~S}$ rRNA was amplified, and the genetic sequence was identified as Arcobacter sp. (Fig. 1).

The isolate identified as Arcobacter sp. was examined by mPCR, using the primers developed by Houf et al. (12) to determine the species. PCRs were performed in a $25-\mu l$ reaction mixture containing $2 \mathrm{ml}$ of template DNA, 2.5 $\mathrm{ml}$ of $10 \times$ PCR buffer, $10 \mu \mathrm{M}$ of each of the primers (ARCO, BUTZ, CRY1, CRY2, and SKIR), $0.2 \mathrm{mM}$ each of the four dNTPs (Fermentas, Germany), and 1.0 U Taq DNA polymerase (Fermentas). $\mathrm{PCR}$ involved initial denaturation at $94^{\circ} \mathrm{C}$ for $3 \mathrm{~min}, 35$ cycles of denaturation $\left(94^{\circ} \mathrm{C}, 45 \mathrm{~s}\right)$, primer annealing $\left(60^{\circ} \mathrm{C}\right.$, $45 \mathrm{~s})$ and chain extension $\left(72^{\circ} \mathrm{C}, 1 \mathrm{~min}\right)$, and final extension $\left(72^{\circ} \mathrm{C}, 7 \mathrm{~min}\right)$. The amplified products were resolved in $1 \%(\mathrm{wt} / \mathrm{vol})$ TAE agarose gel, and the band patterns were analyzed in the gel documentation system (Vilber Lourmat, France). Sterile distilled water served as the negative control. The mPCR showed that the strain was A. butzleri (Fig. 2).

For the purpose of species identification, DNA sequence analysis of the 1,223-bp genus PCR product was performed. BLAST analysis showed the sequence to have the closest homology (100\%) with the 16S rRNA of A. butzleri (accession numbers DQ464342.1, DQ464341.1, AY621116.1, AF314538.1, U34386.1, and U34388.1).

The antibiotic susceptibility test was performed using a disk diffusion method (13). The A. butzleri isolate was susceptible to amikacin $(30 \mu \mathrm{g})$, erythromycin $(15 \mu \mathrm{g})$, doxycycline $(30 \mu \mathrm{g})$, piperacillin-tazobactam $(100 / 10 \mu \mathrm{g})$, trimethoprim-sulfamethoxazole $(1.25 / 23.75 \mu \mathrm{g})$, ciprofloxacin $(5 \mu \mathrm{g})$, levofloxacin $(5 \mu \mathrm{g})$, and nalidixic acid $(30 \mu \mathrm{g})$. The isolate was resistant to ampicillin $(10 \mu \mathrm{g})$, cefuroxime $(30 \mu \mathrm{g})$, and clindamycin $(2 \mu \mathrm{g})$ (antibotic disks from Oxoid). The patient was treated with $1 \mathrm{~g}$ of ciprofloxacin/day for 7 days. His symptoms subsided within 2 days of the initiation of antibiotic therapy.

\section{Discussion}

Although several reports describe the isolation and identification of arcobacters from different sources, especially from animals and the environment $(10,14-16)$, to our knowledge, no publications describe the recovery of arcobacters from human infections in Turkey. Arcobacters were first described in the 1970s by Ellis and colleagues, who isolated these organisms from aborted fetal tissues of pigs and cattle. Because of their similarity to campylobacters and their ability to grow aerobically at $30^{\circ} \mathrm{C}$, they were originally considered to be aerotolerant campylobacters (1). After detailed taxonomic studies, these microorganisms were later included in the genus Arcobacter (17). Our isolate was catalase, oxidase, and nitrate reduction positive but urease and $\mathrm{H}_{2} \mathrm{~S}$ negative. The isolate grew on MacConkey agar at 15 and $25^{\circ} \mathrm{C}$ and was susceptible to nalidixic acid but resistant to cephalothin.

In our case, the patient had eaten barbecued chicken 1 day before the onset of his diarrheal symptoms. Considering that Arcobacter species are commonly isolated from various animal sources, especially poultry $(14,15)$, it seems possible that the source of our patient's infection was improperly cooked chicken. Because arcobacters have been isolated from the stool specimens of healthy people (18), another stool specimen was collected from our patient 1 month after the onset of the illness and cultured for the presence of arcobacter by using direct-plating and enrichment techniques. However, this time A. butzleri was not isolated from the patient's fecal specimen.

In several countries, A. butzleri has been reported to cause acute gastroenteritis and chronic diarrhea in humans. An outbreak caused by A. butzleri was reported in an Italian school (19). This outbreak involved 10 children who complained of abdominal pain without diarrhea. Lerner et al. (20) recovered $A$. butzleri from two hospitalized patients with diabetes mellitus type I, hyperuricemia, and alcohol abuse, who complained of diarrhea and abdominal cramps. In Chile, Fernandez et al. (21) isolated A. butzleri from two patients with chronic diarrhea, and in another study (22), A. butzleri was found at a prevalance of $8 \%$ as an etiological agent of travellers' diarrhea in Mexico, Guatemala, and India.

To our knowledge, this is the first reported human case of acute gastrointestinal infection caused by A. butzleri in Turkey. In light of this case, it is

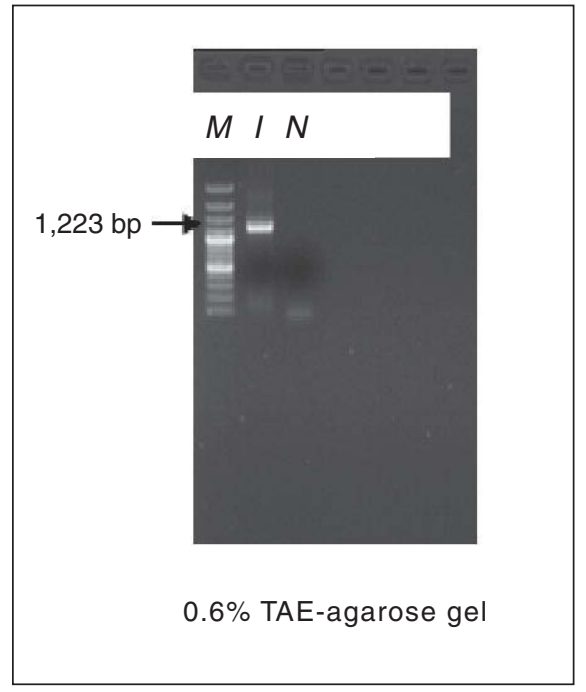

Figure 1. Identification of representative Arcobacter isolate to the genus level by PCR. M, marker (100 bp plus DNA ladder); $\mathrm{I}$, the isolate; $\mathrm{N}$, negative control.

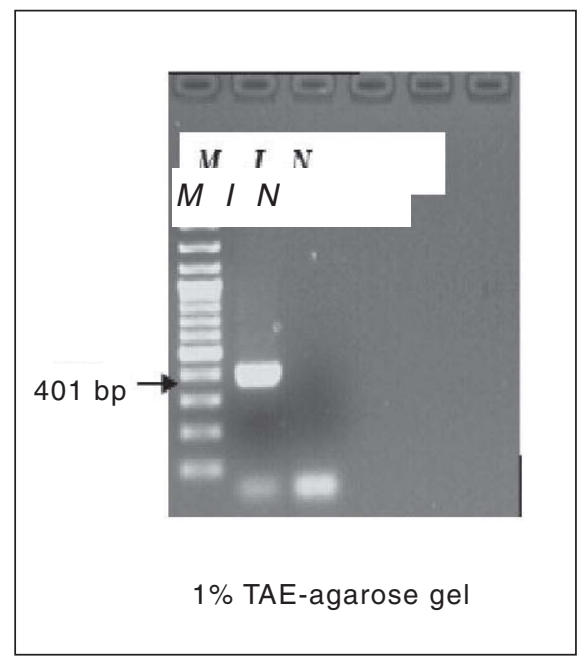

Figure 2. Identification of representative Arcobacter isolate by mPCR. M, Marker (100 bp plus DNA ladder); I, the isolate; $\mathrm{N}$, negative control.

recommended that $A$. butzleri be considered a possible cause of gastroenteritis in humans

References

1. Vandenberg, O., M.B. Skirrow, and J.P. Butzler. 2005. Campylobacter and Arcobacter, p. 1541-1562. In S. Borriello, P. Murray, and P.R. Funke (ed.), Topley \& Wilson's microbiology and microbial infections, 10th ed. Edward Arnold Ltd., Italy.

2. Lehner, A., T. Tasara, and R. Stephan. 2005. Relevant aspects of Arcobacter spp. as potential foodborne pathogen. Int. J. Food Microbiol. 102:127-135. 
3. Snelling, W.J. et. al. 2006. Under the microscope: Arcobacter. Lett. Appl. Microbiol. 42:7-14.

4. Collado, L. and M.J. Figueras. 2011. Taxonomy, epidemiology, and clinical relevance of the genus Arcobacter. Clin. Microbiol. Rev. 24:174-192.

5. Figueras, M.J. et. al. 2011. Arcobacter ellisii sp. nov., isolated from mussels. Syst. Appl. Microbiol. 34:414-418.

6. Burnens, A.P., U.B. Schaad, and J. Nicolet. 1992. Isolation of Arcobacter butzleri from a girl with gastroenteritis on Yersinia selective agar. Med. Microbiol. Lett. 1:251-256.

7. On, S.L., A. Stacey, and J. Smyth. 1995. Isolation of Arcobacter butzleri from a neonate with bacteraemia. J. Infect. 31:225-227.

8. Yan, J.J. et. al. 2000. Arcobacter butzleri bacteremia in a patient with liver cirrhosis. J. Formosa Med. Assoc. 99:166-169.

9. Lau, S.K. et. al. 2002. Identification by 16S ribosomal RNA gene sequencing of Arcobacter butzleri in a patient with acute gangrenous appendicitis. J. Clin. Pathol. Mol. Pathol. 55:182-185.

10. Aydin, F. et. al. 2007. Prevalence and distribution of Arcobacter species in various sources in Turkey and molecular analysis of isolated strains by ERICPCR. J. Appl. Microbiol. 103:27-35.

11. Harmon, K.M. and I.V. Wesley. 1996. Identification of Arcobacter isolates by PCR. Lett. Appl. Microbiol. 23:241-244.

12. Houf, K. et. al. 2000. Development of a multiplex PCR assay for the simultaneous detection and identification of Arcobacter butzleri, Arcobacter cryaerophilus and Arcobacter skirrowii. FEMS Microbiol. Lett. 193:89-94.

13. CLSI. 2010. Performance standards for antimicrobial susceptibility testing 20th informational supplement. M100-S20. CLSI, Wayne, PA.

14. Atabay, H.I. et. al. 2002. The prevalence of arcobacters on chicken carcasses sold in retail markets in Turkey and identification of the isolates using SDS-PAGE. Int. J. Food Microbiol. 81:21-28.

15. Ertas, N. et. al. 2010. Investigation of the existence of Arcobacter species in environmental water resources and raw milk by multiplex PCR. J. Food Protect. 73:2099-2102.

16. Atabay, H.I. et. al. 2008. Isolation of various Arcobacter species from domestic geese (Anser anser). Vet. Microbiol. 128:400-405.
17. Vandamme, P. et. al. 1992. Polyphasic taxonomic study of the emended genus Arcobacter with Arcobacter butzleri comb. nov. and Arcobacter skirrowii sp. nov., an aerotolerant bacterium isolated from veterinary specimens. Int. J. Syst. Bacteriol. 42:344-356.

18. Miller, G.W. et. al. 2009. First multilocus sequence typing scheme for Arcobacter spp. BMC Microbiol. 9:196.

19. Vandamme, P. et. al. 1992. Outbreak of recurrent abdominal cramps associated with Arcobacter butzleri in an Italian school. J. Clin. Microbiol. 30:23352337.

20. Lerner, J., V. Brumberger, and V. PreacMursic. 1994. Severe diarrhea associated with Arcobacter butzleri. Eur. J. Clin. Microbiol. Infect. Dis. 13:660-662.

21. Fernandez, H., S. Krause, and M.P. Villanueva. 2004. Arcobacter butzleri an emerging enteropathogen: communication of two cases with chronic diarrhea. Brazil J. Microbiol. 35:216-218.

22. Jiang, Z.D. et. al. 2010. Microbial etiology of travelers' diarrea in Mexico, Guatemala, and India: importance of enterotoxigenic Bacterioides fragilis and Arcobacter species. J. Clin. Microbiol. 48:1417-1419. 